\title{
Children with juvenile idiopathic arthritis currently followed in a tertiary care setting have a better psychosocial well-being than healthy peers
}

\author{
M Bertamino ${ }^{1 *}$, A Consolaro ${ }^{1,2}$, B Lattanzi ${ }^{1}$, S Magni-Manzoni ${ }^{3}$, S Lanni ${ }^{1}$, C Suffia ${ }^{1}$, S Dalprà ${ }^{1}$, S Rosina ${ }^{1}$, A Martini ${ }^{1,2}$, \\ A Ravelli ${ }^{1,2}$
}

From 18th Pediatric Rheumatology European Society (PReS) Congress

Bruges, Belgium. 14-18 September 2011

\section{Background}

Assessment of health-related quality of life (HRQL) is a fundamental component of the clinical evaluation of children with pediatric rheumatic diseases. However, comparison with healthy children $(\mathrm{HC})$ has seldom been attempted.

\section{Aim}

To compare the HRQL of children with juvenile idiopathic arthritis (JIA) with that of $\mathrm{HC}$.

\section{Methods}

669 parents of children with JIA, 398 children with JIA, 801 parents of $\mathrm{HC}$, and $796 \mathrm{HC}$ completed independently the Pediatric Rheumatology Quality of Life scale (PRQL) (Filocamo et al. Rheumatology 2010). Children with JIA and $\mathrm{HC}$ who completed the questionnaire were aged > 7-8 years. The PRQL is a 10-item questionnaire that includes 2 subdimensions, physical health $(\mathrm{PhH})$ and psychosocial health (PsH), each composed of 5 items. The total PRQL score ranges from 0 to 30, with higher scores indicating worse HRQOL. A separate score for the $\mathrm{PhH}$ and $\mathrm{PsH}$ subscales (range 0-15) can be calculated.

\section{Results}

The median PRQL total score in children with JIA and $\mathrm{HC}$ was comparable for both parent proxy-reports (2

\footnotetext{
* Correspondence: martabertamino@libero.it

'Pediatria II, IRCCS G.Gaslini, Genova,Italy

Full list of author information is available at the end of the article
}

and 2, respectively) and child self-reports (2 and 3, respectively). The frequency of 0 scores (=normal HRQL) for the total PRQL score was higher in children with JIA than in $\mathrm{HC}$ for both parent proxy-reports (25.9\% and $22.8 \%$, respectively) and child self-reports (23.4\% and $11.7 \%$, respectively). However the frequency of 0 scores for the $\mathrm{PhH}$ subscale was greater in $\mathrm{HC}$ than in children with JIA for both parent proxy-reports (55.1\% and $36.4 \%$, respectively) and child self-reports (37.8\% and $36.8 \%$, respectively). Unexpectedly, the frequency of 0 scores for the PsH subscale was greater in children with JIA than in HC for both parent proxyreports (43\%\% and $27.5 \%$, respectively) and child selfreports (44.2\% and $17.5 \%$, respectively). Figures 1 and 2 show the frequency of 0 scores for the 10 items of the PRQL, with items 1-5 referring to $\mathrm{PhH}$ and items 6-10 referring to $\mathrm{PsH}$. $\mathrm{PhH}$ items more frequently impaired in JIA patients walking, sports, and pain.

\section{Conclusion}

To our knowledge, our study is the first to show that psychosocial well-being of children with JIA is better than that of HC. This phenomenon may depend, at least partially, on most of the JIA patients currently attending tertiary care hospitals for follow-up visits having well-controlled disease with little or no disease activity or disability. It is conceivable that relief of active disease symptoms leads to a marked enhancement in their mental and social health. This observation deserves further exploration in different populations.

(c) 2011 Bertamino et al; licensee BioMed Central Ltd. This is an open access article distributed under the terms of the Creative 

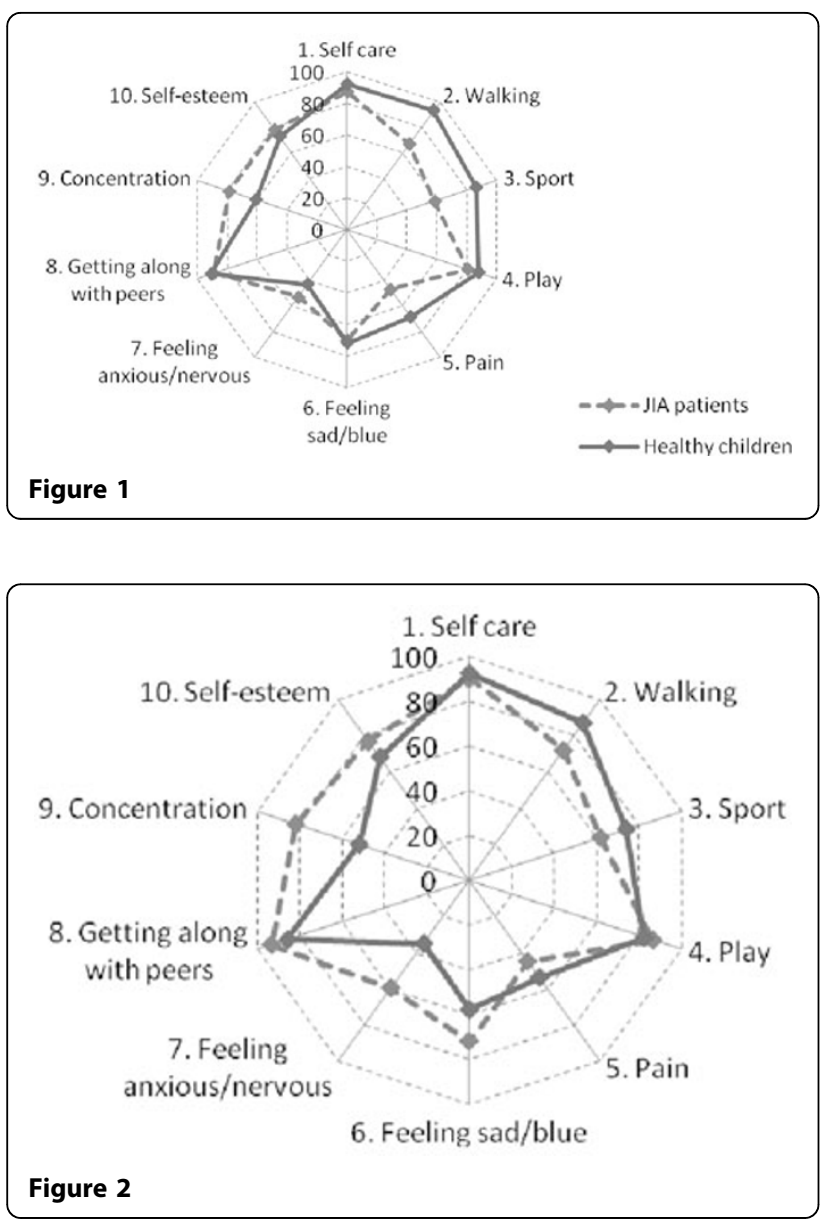

\section{Author details}

'Pediatria II, IRCCS G.Gaslini, Genova,Italy. ${ }^{2}$ Dipartimento di Pediatria, Università degli Studi di Genova, Italy. ${ }^{3}$ Clinica Pediatrica, Fondazione IRCCS Policlinico S. Matteo, Pavia, Italy.

Published: 14 September 2011

doi:10.1186/1546-0096-9-S1-O22

Cite this article as: Bertamino et al:: Children with juvenile idiopathic arthritis currently followed in a tertiary care setting have a better psychosocial well-being than healthy peers. Pediatric Rheumatology 2011 9(Suppl 1):O22.

\section{Submit your next manuscript to BioMed Central} and take full advantage of:

- Convenient online submission

- Thorough peer review

- No space constraints or color figure charges

- Immediate publication on acceptance

- Inclusion in PubMed, CAS, Scopus and Google Scholar

- Research which is freely available for redistribution

Submit your manuscript at www.biomedcentral.com/submit
C Biomed Central 